\title{
COSTING INFORMATION IN THE UK NHS: \\ THE (NON-) USE OF COST INFORMATION \\ IN THE UK NHS TRUST HOSPITALS
}

\author{
By
}

\section{DILA AGRIZZI}

The University of Southampton, UK

School of Management

\section{Correspondence Address:}

DILA AGRIZZI

28 Langdale Drive

Ascot - Berkshire

SL5 8TQ

England - UK

Email:dila@soton.ac.uk 


\title{
COSTING INFORMATION IN THE UK NHS: THE (NON-) USE OF COST INFORMATION IN THE UK NHS TRUST HOSPITALS
}

\begin{abstract}
This paper aims to examine empirically the development and usage of cost information in the UK National Health Services (NHS) in order to provide information on how it is currently used and how it might be used in the future. The issues of costing healthcare service have been discussed internationally, in the light of the Diagnostic Related Groups (DRGs). The findings suggests that, in the UK, despite the introduction of Health Resource Groups (HRGs), there is no indication that the Department of Health has any direct interest in pursuing the consideration of HRGs as a control device. Therefore, the micro effect is a decoupling from cost control at the organisational level. The paper adds to our understanding of the nature of the interaction between the macro steering process and the micro effects. The analysis of the data follows Habermas' (1984) discursive process, which involves marshalling evidence, informed by a 'middle range' methodology (Laughlin, 1995, 2004) to develop a convincing argument concerning a particular situation.
\end{abstract}

Key works: DRGs, HRGs, cost information in hospitals. 


\section{COSTING INFORMATION IN THE UK NHS: THE (NON-) USE OF COST INFORMATION IN THE UK NHS TRUST HOSPITALS}

\section{INTRODUCTION}

The efficient use of resources in healthcare is important because inefficiency means wasting resources that could be available to provide care for those in need. The UK NHS legislation reinforces the view that this efficiency can be achieved by implementing cost/resourcecontrol mechanisms. This has previously been operationalised through the internal market and various changes to the health services administrative structures (Ham, 1999). The current UK NHS contracting process between providers and purchasers of healthcare adopts Health Resource Groups (HRGs), which are designed to group together episodes that are clinically coherent and consume similar amounts of resource. However, HRGs are not used as a means of distributing or controlling resources. In other nations, unlike the UK, the recourse to cost/resource control has been more explicit and it has been operationalised using systems of Diagnostic Related Groups (DRGs) ${ }^{1}$. This study is concerned with an exploration of costing for control in the UK NHS in the light of the NHS model of control introduced by the New Labour Government (1997 White Paper). It aims to explore ways of improving systems of control and to provide information on how costing is currently used and how it might be used in the future within the UK NHS.

The paper discusses the nature of the interaction between the macro steering process and the micro effects. It discusses the nature of the Government attempts to steer the NHS organisations. The paper examines empirically how cost information is developed and used in a particular NHS Trust, in the light of the organisational members' perspective. It reveals that costing information is, at a certain extent, rejected. This study provides a unique emphasis on the impact of culture on the control systems in the NHS. The research approach adopted is 'middle-range thinking' (Laughlin, 1995, 2004), Laughlin's (1991) and 
Broadbent \& Laughlin's (1997) theoretical models for understanding organisational and accounting change. This theoretical combination is of an interpretative nature and, as such, it provides a language to discuss both the opportunity to build some understanding about the dynamics of the relationship between the societal level (the Department of Health) and the organisational level (the NHS organisations) and the issues of accounting change in organisations.

The findings of the paper indicate that, although benchmarking in the UK NHS is not new (Jones, 2002), it has become compulsory, following the abolition of the quasi market (in which cost was perceived as necessary to price the outputs provided). The introduction of a system supported by benchmarking reinforced the need for a comprehensive and consistent policy to costing. The introduction of the Long-Term Service Agreements (LTSAs) initiative reflects the operationalisation of this approach (HSC 1998/198), as it implies that the budget allocations to the NHS Trusts should be linked to activities, according to a local health programmes (HImPs). It is within this context that all NHS acute Trusts should set their services agreement on a long-term basis. The most extensive changes have been developed within this perspective and, therefore, financial control of spending limits has become more visible through the introduction of the star-ratings system, which has financial control as one element (The NHS Performance Ratings for Acute Trusts, 2000/2001). Therefore, cost control remains a key element for consideration and this requires empirical examination.

The paper is organised in the following fashion: Section 2 addresses the theoretical and methodological approach. It also provides a broad overview of the profile of the organisation that informs the basis of this case study. Section 3 develops a contextual understanding of the NHS current approach to resource control and, therefore, it briefly reviews the 
approaches to costing/resource control and how these have been developed in the UK NHS. This section also provides a brief overview of the approaches to costing healthcare within the international context, in order to locate the UK. Section 4 focuses on the findings and the final section concludes the paper and provides directions for further research.

\section{METHODOLOGICAL AND THEORETICAL FRAMEWORK}

As this study illustrates a case of a macro steering $(\mathrm{DoH})$ trying to regulate the systems (the NHS organisations) in the light of the lifeworld that informs the macro steering (DoH), it adopts Broadbent and Laughlin's (1997) theoretical model. This model is built on the notion of control and design archetypes (Greenwood and Hidings, 1988) ${ }^{2}$ and, as such it provides a mode of theorising the control systems of an organisation, linking them to societal processes of control. This theoretical framework is complemented by Laughlin's (1991) model of organisational change, which allows the application of the notion of 'absorption'3 at the micro level. Similar themes, concerns and conclusions are apparent in other studies, which address issues regarding the roles of accounting information in hospitals (e.g. Nyland and Pettersen, 2004; Lapsey, 2001; Covaleski and Dirsmith, 1983). This paper confirms the findings of previous literature and it provides an indication of the nature of the decoupling from cost control perceived within the NHS organisations.

This paper adopts a broad methodological perspective, which allows recognition of the importance of the context in which organisations operate and this is a relevant aspect in seeking to explore the issues concerning control processes in healthcare. 'Middle-range thinking' provides an analytical framework that can be used to build some understanding of the changing processes in organisations (Laughlin, 1995, 2004). It is within this perspective that this study undertook an empirical investigation into a particular NHS organisation and it adopted various methods of data collection. In line with the methodological approach, a 
sample of medical personnel and management team were formally and informally

interviewed. The analysis of both the DoH legislative documentation and the documentation of this particular NHS Trust formed the basis for the empirical investigation. The study extended to formal and informal meetings. The researcher's attendance to the Trust's public board meetings (1999-2002) became a rich source of information. Observation was an inherent and relevant part of the research process. The analysis of the empirical investigation is a result of the triangulation of all the data collection methods adopted in comparison with other issues that emerged in the informal and observational findings (Ryan et al., 2002). The analysis of the data follows Habermas' (1984) discursive process, which involves marshalling evidence, informed by a 'middle range' theory to develop a convincing argument concerning a particular situation.

\section{The Organisation Profile}

The organisation, which is the focus of this study, is the largest non-teaching NHS acute Trust in the South of England. This factor was significant to justify the choice of this particular organisation. The NHS Trust under consideration is composed of two hospitals covering a population of approximately 450,000. It employs approximately 2,692 people, evenly situated between two sites located about 30 miles away from each other. Different physical aspects between the sites were observed and this seems to impact on the Trust's management control issues. As an assurance of confidentiality was given, the hospitals are named 1 and 2. Hospital 1 is located in a large greenbelt and wealthy area. Its main entrance is peculiar, seeing as it reflects a shopping centre environment, which indicates some attempts to develop a patient-friendly environment as well as to generate extra revenue by renting out retail space. Hospital 1 houses all the Trust's management. The Finance Department is located in a building, which was originally an old-fashioned Nightingale-style ward and, hence, at the edge of the hospital environment, with its main entrance 
symbolically facing the resuscitation room. Whilst it is part of the organisation, it is placed on the fringes of the hospital. Although Hospital 1 is situated in a privileged area, there are issues concerning its location, which are critically interfering with both its quality of the service delivery and its general financial situation. Its location has impacted on nurses and carers' recruitment and retention problems and this is perceived as a key issue. Many aspects are seen as causal factors that aggravate this problem, such as the high housing cost in the surroundings; the active private medicine; poor transportation links, the paucity of social activities and the pressure resulting from the increasing demand in A\&E.

Hospital 2, unlike Hospital 1, is run in a central small urban area, next to a busy road and surrounded by social facilities, where housing cost is not seen as a concern. Perversely, the staff employed by Hospital 2 are entitled to London weighting and, hence, their wages are higher than Hospital 1. As a result, Hospital 2 has lower staff recruitment and retention problems compared to Hospital 1. Ironically, the workload intensity in hospital 2 is considerably lower than hospital 1, because of the merger ${ }^{4}$. Therefore, Hospital 2 is not big enough to stand by itself and, although its staff turnover is not an issue, its small site leaves little possibility for expansion of activity. Consolidating activities to ensure that effective care is provided has been challenging for this particular NHS Trust.

\section{Financial Situation}

The local Health Authority (HA) reports that this NHS Trust presents, in absolute value, the greatest deficit within the region. While the HA considers that management control issues are key aspects of the Trust's difficult financial situation, the HA's managers were unable to provide any further details about it. The NHS Trust's Financial Report on 31/01/03 presents a deficit of approximately $£ 2,500.000$ and this represented $3 \%$ of its annual budget. Its out turn for 2003 was a cumulative overspend resulting in a deficit of approximately $£ 4,800,000$ 
(Financial Report, $31^{\text {st }}$ of March 2003). The main overspending directorates were those most directly affected by increased activity and recruitment and retention problems, such as Medicine, Accident \& Emergency (A\&E) and Anaesthetics. The highest expenditure in these areas relates to agency and bank staff ${ }^{5}$, which are necessary to minimise the recruitment and retention issue. The cost of hiring agency and bank staff is a key problem, since it costs $50 \%$ more than hiring staff employed by the Trust. The cost of constantly moving consultants between both locations, due to the split-site working, is considered high which has caused further problems for the Trust's financial position. Its financial situation was further aggravated by the fact that the health economy entered into a period of significant change in 2001, which involved revision of both financial and functional aspects. The HA that contains this Trust was facing a substantial accumulated deficit in 2001. As a result, the need to generate significant additional savings had become a priority over the three-year period (from 2001 to 2003). As a result, this Trust had undertaken a savings programme to minimise the deficit faced by the region.

\section{A MACRO PERSPECTIVE}

\section{New labour - inter-agency collaboration}

The literature has, for some time, been concerned with the UK State's attempts to keep control of resources by introducing control mechanisms and accounting systems (Preston, 1992; Purdy, 1995). Most authors have examined the Conservative Governments' initiatives to ensure efficiency and provide mechanisms for pricing introduced in the NHS internal market (e.g. Le Grand, 1994; Ferlie, 1994). The issues of commissioning healthcare service within the quasi-market approach have been debated in previous literature (e.g. Barker et al.,

1997; Flynn \& Williams, 1997). Some authors argue that, in the previous Government, costing for contracting purposes and the overall role of accounting became more sophisticated, taking an entrepreneurial approach (Lapsley and Pettigrew, 1994; Richardson 
and Cullen, 2000). However, there is the argument that providers of healthcare used different costing approaches, which led to a paucity of comparability (Ellwood, 1996c).

Notwithstanding the various attempts to develop costing, the literature argues that the Conservative Government's policy of competition between providers and choice for patients did not deliver the efficiency and responsiveness expected (Propper and Bartlett, 1997). A range of elements was suggested as causal factors, including the need of a consistent approach to costing.

In trying to attenuate the effects of competition resulted from the internal market, the Labour Government introduced the notion of 'an integrated care model' through the implementation of a new NHS model of control (1997 White Paper). This included the introduction of the Long-Term Service Agreements - LTSAs (HSC 1999/243), which were seen as a means of minimising the conflicts between providers and commissioners and tackle fragmentation at the local level (which seemed to be created by the internal market). The LTSAs initiative implies that the budgets allocated to the NHS Trusts should be linked to activities (HSC 1998/198). Within this context, all NHS Trusts should set their Services Agreement on a long-term basis and according to the Health Improvement Programmes (HImPs). The Government's expectation was that the LTSAs' initiative replaced the short terminism of the market, in order to provide the stability needed to ensure appropriate access to high quality services across the country (equity). It is in this sense that long-term contracts (from 3-5 years) replaced one-year contracts between providers and commissioners. In practice, the level of service activity and the financial investment (required from all NHS Trusts through LTSAs to achieve key targets) should be set in the annual Service Financial Framework (SaFFs). This process should provide the basis upon which the health needs (including aspects of equity and quality) could be reflected in the financial planning. This approach is similar to a previous initiative introduced by the Conservative Government, which aimed to 
facilitate the contracting process by introducing the concept of a long-term relationship (Fattore, 1999). It was also a strategy to reduce costs; since the internal market was considered costly (Ham, 1999) and also because there is the assumption that long-term agreements diminish the frequency of negotiations of prices and products, allowing providers to manage their costs better (Jones, 1999, 2000).

"A key issue in contracting for health service is how to ensure that providers deliver appropriate standards of treatment while keeping costs down" (Barker et al., 1997:82).

It was within this perspective that the NHS model of control introduced a new emphasis on standards and outcomes of services, along with a system supported by benchmarking, which reinforced the need for a dependable approach to costing. This approach was manifested in the mandatory requirements regarding the NHS cost-control guiding principle (HSC 1999/098, page 18).

This policy was operationalised through the National Reference Costing Exercise (NRCE, June 2000), which is part of an extensive set of performance measurements introduced by the Government (High Level of Performance Indicators, 1999) that compose the National Performance Framework (NPF). The NRCE's main objective was to serve the NHS Trusts with the opportunity to recognise cost differences and understand the reasons behind variances ((HSC 1999/098)). The NRCE is composed of three main sets of information: The National Schedule of Reference Costs (NSRC), the National Reference Costs Index (NRCI) and the HRGs. The NSRC sets out mandatory requirements and guidance for the costing of acute services in order to compare costs and, consequently, allows the Government to tackle variances at the local level (First Class Service, 1999). According to the NSRC Guidance, to 
which the NHS Trusts are subject, they are required to make costing information available to local commissioners and to the NHS Executive within a given timescale. The NSRC suggests that costing control should be undertaken in a collaborative way at the local level to facilitate meaningful discussions between providers and commissioners of healthcare on variations in the cost of service (HSC 1998/163 and HSC 1999/098). The NSRC and Activities Requirement provide detailed guidance on the national approach to costing and, hence, it details the range of services to be costed at HRGs, which are developed from national data. The NRCI aims to rank hospitals according to their index value, to serve comparison purposes. This index is calculated by dividing a hospital actual total cost (HRG cost $x$ number of HRGs) by its expected cost (national average cost $x$ the number of HRGs).

In seeking to provide a detailed framework to be followed by the NHS hospitals, the Department of Health launched the NHS Cost Manual (2000), whose aim (as its predecessor) is to introduce a more standardised approach to the treatment of cost and activity and to seek to improve comparability in cost information. Within this framework, Healthcare Frameworks are tools designed to compare aggregated data on people, patients, their treatment and its outcome. They plot groups of people with similar health conditions and expected outcomes given similar interventions (Health Benefit Groups-HBGs) against groups of interventions that are similar in resource use and clinical meaning (HRGs). HRGs are, thus, an attempt to get away from average speciality costs and move to a more sensitive measure by breaking down specialities into different groupings, according to the complexity of the procedure. In theory, the costing approach established through the NHS Costing Manual was introduced by the Department of Health to support the NSRC in an attempt to control costs in the NHS Hospitals. This policy follows a long tradition of central control towards the NHS organisations, which implies the possibility of controlling organisational behaviour through the establishment of national targets (Agrizzi, 2003). However, in 
practice, the flexibility of the structure offered by the NHS costing approach and the inherent nature of cost apportionment, means that different NHS Trusts calculate their costs on different bases. The NHS Trusts make their own decisions about using different methods of apportioning costs, since the data are recorded in their systems in different ways ${ }^{6}$. In practice, therefore, the reference cost (and, then, HRGs) compares hospitals on different bases and this implies that HRGs produced by individual NHS Trusts cannot be directly comparable. The findings in this paper confirm previous literature that has shown evidence that the NSRC is not robust enough for comparisons and, as a result, cost variation between NHS Trusts cannot represent real efficiency differences (Llewellyn and Northcott, 2001; 2003).

\section{World-Wide approaches to cost control}

Within the international context, hospitals have adopted different approaches in order to set their budget. In general, it has been a move from open-ended retrospective funding of hospital activities to the establishment of prospective budgets. One means of dealing with the issue of linking payment to activity is using DRGs combined with the Prospective Payment System (PPS) and this procedure has been used in the wide-world context to control the increasing public cost in healthcare. In the first instance, DRGs were created as a tool for better management in organisations, especially in hospitals, because it demands the involvement of clinicians in the accounting and cost process in the context of control (Lehtonen, 2000). However, there are issues concerned to DRGs' functioning (see e.g. Fetter and Freeman, 1986 and Fetter, 1991). Most literature deals with the general related effects of the DRGs on hospitals (see e.g. Chua \& Preston, 1994 and Charpentier \& Samuelson, 1996). There have been many studies addressing issues regarding the implementation of DRGs in hospitals in particular countries, for example, in France, (Halgand, 2000), in Italy (Garattini et al., 1999) and in Norway (Pettersen, 2001). All these authors refer to DRG as a popular technique used in contracting processes in the worldwide perspective, despite the fact that 
there are issues concerning its implementation. Due to the considerable popularity of the DRGs and PPS internationally, it is interesting to note the lack of discussion of their use in the UK. The UK has not followed international trends, which is the adoption of the DRGs as a management and control mechanism in hospitals as well as to act as a pricing mechanism. The UK has introduced HRGs as control mechanism, but in a much less intrusive way than DRGs in other countries. In practice, the UK moved towards developing its own way of costing and budgeting healthcare. However, the question why the notion of costing activity by adopting HRG has not reached the local level is not only pertinent, but intriguing. In this sense, the NHS is still in the early stages of a long-term process of change.

\section{A MICRO PERSPECTIVE}

\section{The Organisational Design Archetypes:}

In order to accomplish the demands of the NHS Cost Manual, this Trust implemented a costing information system, called 'Plan B' processed by PRECISION+, which is a Windows application. The allocation of its structure was developed under a top-down model and it illustrates how the elements defined by this organisation are linked to produce a unit price. The cost application shows that overhead costs were initially absorbed into patient treatment services support service and patient treatment service cost centres, in line with the NHS costing principles and concepts. Allocations based on activity data allow total absorbed cost to be grouped and allocated to speciality level. The allocated costs were distributed across the range of points of delivery within each speciality. From these points of delivery, the system produces a unit cost per speciality and patient type. Alternatively, it can break down the cost further, using procedure level activity information and weighting factors, to produce procedure unit costs. If required, the system can also generate a unit cost per local group. For instance, overhead cost and support service costs can be allocated directly to patient treatment cost centres, according to the NHS Costing Manual. By grouping HRGs, 
Precision+ produces sets of $\mathrm{HRG}$ reports, calculating and reconciling average costs of procedures by point of delivery across specialities. This NHS Trust defines 39 different groups of specialities. The criteria used to allocate indirect costs within this organisation depend on the availability of information. For example, there is a lack of data about the details of the hospitals activities; there is no record of how exactly clinicians spend their time seeing patients. The costing information related to clinical work is generally built from data informally gathered from medical personnel. There is a lack of basic information such as the area of the hospital building, which could be used to allocate overhead cost (e.g. heating costs). The casualness that cost information is dealt with confirms the debates that have been raised in the literature about the concerns of adopting reference costs for comparison. Nonetheless, in official terms, the cost control demands are met in line with the DoH costs' guidelines. However, in the context of perceived organisational requirements, the situation is different and it leads to the question of what the cost information is used for.

\section{The Organisational Interpretative Schemes}

Regardless of the fact that the official obligations are met, in practice, costing information produced by this organisation is, at its best, loosely coupled to organisational activities. It has only served the purpose of meeting the NRCE requirements and, hence, is not linked to the organisation's management at any stage. The Finance Team's main concern is with the global budget situation:

"At the end of the day, mine is a job that sits outside everybody's work. Everybody else's work in the Trust is more concerned with the functional budget and, hence, how much money they have left for the current year... As far as I am concerned, nobody uses cost information for internal purposes...From an external point of view? Well, nobody has come back to me asking questions about the cost information that I have prepared and released ... and this is the case of all other 
NHS Trust..." (Finance Manager 1, in charge of the implementation of the costing system required to compose the $\mathrm{NRCE}$ ).

Despite the fact that the NHS Trusts' income should be negotiated through Long-Term Service Agreement (LTSAs) including a linkage between activities and income (and then the use of HRGs), this policy was not yet entirely visible in practice within this Trust, where the annual SaFFs are still based on historical data. Thus, HRGs are not adopted in commissioning healthcare, although its adoption is explicitly set up in the legislation as a means of linking income to activity:

"Contracts are negotiated with the Health Authority in an annual cycle and an historical-based term. It has been like this for years". (Financial Manager 1)

Nonetheless, according to the Modernisation Fund initiative ${ }^{7}$, extra income can be allocated to HA to tackle local priorities and to complement the budget allocated to NHS Trusts. However, the fact that income is not linked to activities has aggravated this Trust's financial debts, because there is an increase in the demand in general and, in particular, in the A\&E Department (approximately 4\% per year - the Activity \& Finance Report, Dec-2001) (see also Jones and Dewing, 1997; Lapsley, 1997 and Model and Lee, 2001). This fact contradicts the Reference Costs approach, which is to facilitate and allow discussions between providers and commissioners on variations in the cost of service. Evidence shows that discussions within this Trusts and amongst HA and PCGs (Primary Care Groups) do not involve, at any stage, debates about Reference Cost or the use of HRGs in commissioning:

'Cost information is not used for any external or internal purpose at any stage within the Trust... not that I'm aware of. Issues of cost are not raised in our 
meetings, but we are concerned about keeping control of resources all the time.'

(Finance Manager 2) (Emphasis added)

Whilst reducing expenses was a concern constantly raised, issues related to cost-control or/and HRGs were never part of the agenda in the Trust's board meetings attended by the researcher. The management concerns evolved around the demands of the key targets, established through the star-ratings systems and this included keeping the organisation within a balanced budget. Thus, cost-control issues were placed aside. Whilst the management team was mostly troubled with global budgeting issues, and they had focussed on means of diminishing the problems of resource-constraints, minimal attention was paid to the possibility of using costing information (or HRGs) to provide them with some understanding of the Trust's difficult financial situation. Resource control was performed in a contradictory way, rather than based on any engagement with costing information.

\section{Contradictory ways to approach the issues of resource control}

The strategy adopted by this Trust to control expenses relates to the nature of the service that the Departments provided and on what was alleged to be an efficient way to reduce expenses. Within this Trust, it is at directorate level that the directors are responsible for their costs, and there are different dimensions of the problems in different organisational settings. In the A\&E Department, for instance, the strategy to reduce expenses is to limit the use of the most expensive medicines.

"We (Consultant Directors) say to them (Junior Doctors) that, unless there is a good reason to use the more expensive drugs, they should use the cheapest ones. But, now we have got a problem, because there is some evidence that some expensive drugs are slightly more efficient than the cheapest ones. Therefore, if a thirty-year 
old patient comes with a heart attack diagnosis, the doctor tends to use the more expensive drug, because the cost benefit looks higher. On the other hand, a 55 years-old patient will get the cheapest drug, because it is not very clear whether the result between the different types of drugs is very relevant". (Emphasis added) (A\&E Consultant 2)

$A \& E$ relies on cutting cost by restricting the use of expensive medicine, because there is the assumption that saving could easily be achieved by controlling the consumption of expensive drugs. The A\&E's constant attempt to reduce the utilization of a particular expensive drug prescribed in heart-attack diagnosis (which unit cost is approximately $£ 600$ to $£ 800$ ) is an example that illustrates this assumption. However, further investigation carried out on the A\&E expenditures revealed that the highest expenditure in the A\&E did not relate to the consumption of that particular expensive drug, but to penicillin and paracetamol. These are considered low-cost drugs, although they represented a significant portion of the total expenses because of its high level of consumption. The expenditure on costly drugs was, in fact, irrelevant (owing to its low level of consumption) compared to those low-priced drugs. Therefore, the effort to control the consumption of that particular expensive drug had no impact on the overall A\&E spending. On the other hand, if the consumption of those particular inexpensive drugs could be diminished, there would be a positive impact on the A\&E finance position. Nevertheless, achieving savings on these products does not seem to be attainable, given that high levels of consumption are necessary to minimise patients' pain. As it is apparent, achieving savings in A\&E is a challenging task.

On the other hand, Surgery and Medicine Departments' strategy to control expenses included the closure of wards because it represented a save on staff costs. This approach 
cannot be applied in the $A \& E$, since it must be run within a minimum secure number of nurses (as it is not able to control the flow of incoming patients). Controlling expenditure by reducing nurse hours became a common feature within this NHS Trust, in attempt to minimise its financial difficulties. In the medical speciality, for example, while the national recommendation rate is to keep one nurse per bed per 24 hours (three shifts), the Trust's rate during the course of this empirical investigation were 0.8 nurses per bed. This meant that, due to budget constraint, this Trust kept $20 \%$ fewer nurses in the ward than it should. Closing wards improved staff morale, since it diminished the pressure on them and it allowed the recruitment of nurses on other surgical wards. However, it meant that beds were lost permanently. As shortage of bed leads to cancellation ${ }^{8}$ of operations, an unavoidable negative effect on the waiting-list achievement took place. Two medical wards were closed during the course of this empirical investigation, in an endeavour to achieve savings of $£ 350,000$, as part of the Performance Improvement Plan set in the Southeast region. Yet, this Trust was not able to meet the financial targets established by the ratings-system.

The examples above support the notion that using unit/activity cost information for control is not part of the organisation's interpretative schemes, despite the pressure to control resources exerted by the macro steering media $(\mathrm{DoH})$. Within this Trust, the management team assumes that cost control and budget issues is a finance team's concern and that clinicians are not interested in engaging with this matter. This was the main reason given by finance managers to justify the lack of interaction between finance and medical personnel:

"Doctors do not worry about cost issues. They are not interested in HRGs, but concerned about their own research... You know, it is not their business... I tried very hard to get some information to try to cost activities to compose the reference 
cost... going around here and there, talking to nurses... and could not get much." (Finance Manager 1)

On the other hand, clinicians state that they are interested in cost-control matters, but the Trust's management team does not promote integration between medical personnel and finance to facilitate their engagement, at any level:

"In general, finance people are sitting in there (in the Finance Department) producing figures instead of getting outside their office to talk to the people like me (Consultants) who have influence...It is quite comfortable to be seated out there...they have got to talk to us! It is dirty out here! I'm sure that there is a strategic plan out there, but on the ground, I have not seen any clear evidence of that to look forward." (Consultant 1)

Consultants' perception is that the Trust's management team is not interested in engaging doctors with the management decision in a more holistic way:

"There has been a lack of dialogue between us (Consultants) and the Management Team about having a discussion and debate about what goes on in financial terms. I mean: What are we doing? What are we spending our money on? Can we look at that? But, nothing happens! I have not had a conversation about cost control in any more detail in the last 5 years!". All we hear is that we need to control the budget! (Consultant 3) (Emphasis added) 


\section{Budget Issues}

The Trust's internal budgets are assigned by department (directorates) on an historical basis. The main historical estimations refer to staff wages and supplies. As mentioned earlier, there is no routine adjustment for activity-level expected other than based on the historic information. The Accountant Directorates are in charge of budgetary control. This control process occurs by informing the budget holders, on a monthly basis, how much they have spent and how much they have left throughout the current year. Clinicians' understanding is that they would rather deal with their own budget, if it was assigned to their own specialty, because they consider that they can manage it rather better.

"We should have our own budget to spend the way we wish. It got to be better! If we had our own budget, we would look after it carefully. We (as everybody else) would try to manage our system better. Now it is lost! At the moment there is no incentive, no scheme to be followed. We, more or less, do what we want, really." (Consultant 4)

Within this Trust, financial elements override most aspects. The local Health Authority confirmed that extra income was being transferred to this NHS Trust, in the light of the Modernisation Fund's scheme. However, the Trust's Financial Team verified that this extra income was being used to ease the Trust's financial deficit. On the other hand, Consultants expressed their disappointment with management team's decision:

"Some months ago (March-2002) we had extra money from the Health Authority to do more of a particular kind of operation ${ }^{9}$ in order to cut the waiting list down to three months. This money was allocated to our speciality. We thought that this was wonderful, because, as you know, there is a lot of this particular disease out there! 
But, the end of the year came and clearly part of this money was taken away and used for something else, which we had no information about it!!! (Consultant 3)

Financial pressures within this NHS Trust mean that when the end of the financial year approaches, it becomes more challenging for the management team to keep within a balanced budget. As the financial burden increases, they pass their apprehension onto medical personnel who believe that, whilst they are prevented from engaging with the Trust's decision throughout the year, they are approached by the Management Team only at the end of the financial year to be required to control resources.

"Finance people do not come to us to inform us of what is going on! But, by the end of $\underline{\text { the financial year they go: Stop this! stop that! because we have only one quarter of a }}$ million left... That is all that happens here!" (original emphasis) (Consultant 3)

"All the management team talks about is that the end of the year is coming and that the Trust is overspent and, then we must cut resources! That we need to save money or we cannot expand the service due to resource-constraints." (Consultant 2)

In contrast, the procedure to control the budget at other times along the year is simple to inform the budget holders their monthly expenditure.

\section{DISCUSSION}

This paper aims to develop an understanding of how cost information is developed and used as a control device in a particular NHS Trust in the light of the organisational members' perspective. This study illustrates a case of a macro steering trying to regulate the systems (the NHS organisations) according to a perception of the lifeworld that informs the macro 
steering, which is assumed to be acceptable to the micro interpretative schemes (the NHS organisations). It is within this context that the issues are expressed here in two levels of concern: at the institutional steering-media level (macro effects) and at the systems level (micro effects):

\section{Macro Effects}

Despite the fact that the NHS legislation reinforces a comprehensive and consistent approach to cost control and this is expressed through the development of HRGs, there is no suggestion, in practice, that the DoH has any interest in considering HRGs as a control device. Two main aspects support this view: First, HRGs are only adopted to compose the Reference Costs (NSRC), which only serves the purpose of benchmarking. Second, although HRGs are embedded in the UK contracting process, they are still under developed compared with systems in other countries. In the UK, HRGs are used retrospectively, not proactively and prospectively. Unlike other nations, where the use of DRGs has provided an attempt to respond to resource allocation issues, in the $\mathrm{UK}$, the debate is one of allocation of resources and not payment for activity. Noticeably, there are historic and contextual specificities in the different nations that lead to different approaches to funding healthcare. However, the lack of interest in the possibility of adopting any cost-control technique as a control device in the UK remains surprising.

The UK follows its own approach. The current legislation directing the delivery of healthcare implies that it is expected that more activity can be undertaken with existing resources. This policy entails controlling resources by setting budget and performance targets (e.g. Star-Ratings System) while, in practice, cost-control is disregarded. This study confirms the view that the UK NHS reflects a culture that embeds the concept that the 
linkage of costs to an individual's health care is inappropriate (see also Broadbent et al., 1991):

"The culture in this country is that we (clinicians) should be able to do everything without thinking about cost. Nobody wants to be controlled wherever they are any way. However, clinicians in the USA, for example, have only complied with DRGs because DRGs were imposed on them very strongly. Nevertheless, in the UK there is no such thing! If you go around and ask 'What is the cost of opening a package of stitching material? Alternatively 'What is the cost to put gauze on a wound?' Clinicians go: - 'What?' They are not used to thinking about that.' (Consultant 4) (Original emphasis)

"I suspect that I'm more cost-conscious than some doctors. Therefore, I introduced this glue ${ }^{10}$ early as a cost control measure. I think that this comes from my experience of working overseas, in a third world country, where there is very limited resource and huge demand for care. In addition, the patients pay for drugs themselves. Therefore, we have to be aware of cost all the time and, because we knew the cost involved. However, here... you know... the NHS cannot go bankrupt.

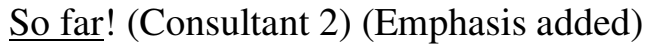

The comments below confirm the assumption that the lifeworld that informs the macro steering embraces the view that the linkage between cost control and healthcare should not be made and that this notion is transferred to the organisational context:

\section{Micro Effects}

Despite the fact that the Trust's Finance Team has introduced a comprehensive and consistent approach to costing control (which adopts HRGs), according to the Department of 
Health demands (NHS Costing Manual), a disengagement with cost-based information is reflected throughout the discourses of both the management team and medical personnel. The unwillingness of the organisational members to engage with financial matters is not a unique finding (see e.g. Knights and Collinson, 1987). However, the lack of interest in costcontrol issues within this organisation includes finance people and this is surprising, considering the financial difficulties that this NHS Trust was experiencing. The view that cost control in healthcare is not accepted is entrenched in the NHS origins and this view is believed to be shared by Consultants. Despite the fact that resource control was an issue raised in every single meeting attended by the researcher, there was no evidence showing that Financial Managers (FMs) had any interest in utilizing costing information to build an understanding of the nature of the Trust's financial problems. They were consumed by the pressure to meet the demands of the key performance indicators, which included keeping a balanced budget. An interesting aspect observed was that FMs tried to cope with financial pressures without involving clinicians and without involving themselves in clinical work. It was apparent that FMs seek to 'absorb' the impact of the macro steering, which, given that this is not very intrusive in term of cost control, it is not as complex as it might be. However, as the financial year approaches and the financial balanced-budget pressure increases, FMs realise that 'absorption' is no longer possible. As the absorbing group, they realise that they are failing and, therefore, they tend to shift into a panic mode and start compelling clinicians to reduce expenses in a more anxious manner. On the other hand, the medical personnel show resentment, because they feel excluded from the Trust's decision-making processes. FMs are seen as creating a set of 'extra' problems to clinicians and, as a result, an 'overspill' situation takes place within this organisation.

The discussion of this case leads to raise several questions such as why do Finance Managers behave in that way? Are Clinicians actually disinterested in cost-control issues? 
Why does not UK Government embrace HRGs (or any other cost technique) as a means of controlling resources? Why is there an emphasis on Performance Indicators instead? Three issues are pertinent to seeking answers to these questions: Firstly, the coupling of cost with activity is perceived within this Trust as 'non-relevant' law (Broadbent and Laughlin, 1997). The fact that HRGs are not attached to operational activities at any stage within this NHS Trust confirms this assumption. Despite the fact that HRGs are calculated in order to ascertain costs of various treatments, the costing system (and, hence, HRGs) is only symbolically constructed. This figurative situation is frequently the case with unspecific and historical attempts to impose technical repairs by attempting to 'control by numbers' (Johnson \& Kaplan, 1987; Ezzamel et al's, 1990:164). This Trust's attempt to fulfil formally the demand of an external imposed law with no major influence and significance within its organisational interpretative schemes portrays a case of first-order change. This situation occurs when the changes are superficial and so they are accommodated by the organisation (see Laughlin, 1991 for more details). A case of second-order change implies alteration in the interpretative schemes and, consequently, on the systems and this might take long time to occur (see also Greenwood and Hinings, 1988, 1993 and Kitchener, M., 1998). However, continuous research to accompany the development of cost-control systems in the NHS is essential to provide further understanding about this issue.

Secondly, the avoidance of this coupling discussed above is a result of the values embedded in the organisation's interpretative schemes, which mirrors the lifeworld that informs the macro steering media. The disinterest in cost-control issues is traceable in the UK NHS culture, which reflects the notion that cost should not interfere in clinical work. Therefore, the values that inform the macro steering processes embrace the assumption that clinicians reject cost-control issues and this is the reason why the adoption of a less intrusive balanced budget performance indicator is preferred as a control device. Within this NHS Trust, 
Finance Managers' behaviour reflects a similar perception (that Clinicians reject cost as a control device) and, as a result, they protect Clinicians from engaging with cost-control matters. The implication is that the effect of this behaviour is a further disengagement between the parties within this NHS Trust.

Thirdly, as it was expressed earlier, cost impinges on clinicians when they are pressurised by the management team to reduce expenses (when the 'overspill' problem occurs). On this occasion, clinicians embrace the perspective that they could manage cost-control issues rather better, especially if they had their budget directly ascribed to their own speciality. Nonetheless, although they claim that they have financial management skills, there is no evidence that they practice this vision within this NHS Trust. As the other organisational members, clinicians rather perform within the NHS culture, which discard cost as a control mechanism.

A final aspect to mention is that the split between the administrative and the clinical worlds perceived within this NHS Trust confirms the findings addressed in previous literature (e.g. Kurunmaki, 2001; Llewellyn, 1998; Jacobs, 2001). However, while preceding studies argue that clinicians' perception on accounting information originates from their professional culture, this study suggests that there is a possibility that the organisational situation override the professionals' ethos of medics that rejects cost as a means of controlling resource in medicine. There is some evidence within this particular NHS Trust suggesting that clinicians are more aware of cost-control issues when they practice private medicine (clinicians practice both public and private medicine within the NHS Trust in consideration). There is an indication that medics have fractured value-sets that lead them to perceive cost/resource control in different ways in different contexts. This supposition raises a pertinent opportunity to further exploring the nature of such split in the interpretative schemes at an individual 
level in order to build additional understanding of the nature of the lifeworld that informs the cost-control processes in the NHS as well as to provide further understanding of the future role for cost control in the NHS.

\section{Notes}

\footnotetext{
${ }^{1}$ Diagnostic Related Groups (DRGs) 'codify' patients into categories of similar treatments and costs and classify 23 major diagnostic categories and 475 DRGs. DRGs served as basis for HRGs and, therefore, HRGs do not differ from DRG in essence.

${ }^{2}$ Greenwood and Hidings' theory implies that the organisational values (the interpretative schemes) inform the organisational steering mechanisms (the organisational design archetypes).

${ }^{3}$ Broadbent and Laughlin's (forthcoming) provide a more detail clarification of this theoretical combination.

${ }^{4}$ The merger of the two hospitals created an issue that raised much local controversy. There is the perception amongst consultants that changes in Hospital 2 have generated some tension in the local community. Local patients feel neglected by the local hospital; since as a result of the changes, they have to travel further to receive treatment.

${ }^{5}$ Bank staff is formed from the Trust's employees, and agency staff are hired from agencies such as the BNABritish Nurses Association.

${ }^{6}$ This was stated by the Finance Team in this particular Trust as well as by a consultancy group hired by the Health Authority to look at clinical pressure within this Trust.

${ }^{7}$ The Modernisation Fund ( $\left.£ 276 \mathrm{~m}\right)$ is the Government initiative launched to help HAs to support the NHS Trusts to tackle waiting-list achievement (HSC 1999/243).

8 During Jan/Feb 2001 - in this NHS Trust, 1133 inpatient operations took place, while 89 were cancelled. This position follows the cancellations' national trend that has risen over the last quarter of that year (March, 2001Board Meeting Report).

${ }^{9}$ Procedure, specialty and disease omitted, in order to protect the identification of the Consultant.

${ }^{10}$ This new glue replaced the traditional stitch, which, although it is cheaper, it demands more medical time.
}

\section{REFERENCES:}

Agrizzi, D. (2003) "Performance Indicators in the UK NHS - a case of a particular NHS Trust", Paper presented in APIRA, July 5-7, Singapore.

Barker, et al. (1997) 'Contracting in the National Health Service: Legal and economic issues' in Flynn and Williams (1997) Contracting for health - quasi-markets and the NHS, Oxford Univ. Press, UK, pp.82.

Broadbent, J. et al. (1991) "Recent financial and administrative changes in the NHS: A critical theory analysis", Critical Perspectives on Accounting, No 2, pp. 1-29.

Broadbent, J. and R. Laughlin (1997) "Contracts, Competition, and Accounting in Recent Legal Enactments for Health and Education Sectors in the UK: An example of Juridification at Work?" in Deakin and Michie (1997), Contracts, co-operation and competition - Studies in Economics, Management and Law. Oxford.

(forthcoming) "Organisational and Accounting Change: Theoretical and Empirical Reflections and Thoughts on a Future Research Agenda", Journal of Contemporary Accounting and Organisational Change.

Charpentier, C. and L.A. Samuelson (1996) "Effects of new control systems in Swedish healthcare organisations". Financial Accountability and Management, Vol. XX, No $\mathbf{X X}$, p.157-171. 
Chua, W.F. and A. Preston (1994) "Worrying about Accounting in health care", Accounting, Auditing and Accountability Journal, No. 7, pp. 5-17.

Covaleski, M. and M. Dirsmith (1983), 'Budgeting as a means for control and loose coupling', Accounting, Organisation and Society, Vol. 8, No 4, p. 323-40.

Ellwood, S. (2000) “The NHS Financial Manager in 2010”, Public Money and Management, Jan-March. p. 23-31.

Ezzamel, M. et al. (1990) "Managing it all by Numbers: A Review of Johnson and Kaplan's Relevance Lost", Accounting and Business Research, Vol. 20, No 78, p. 153-166.

Fattore, G. (1999) 'Cost containment and health care reforms in the British NHS' in Mossialos and Le Grand (1999), Healthcare and Cost Containment in the European Union, Ashgate (Ed), UK.

Fetter, R.B. and J.L. Freeman (1986) 'DRGs: Product Line Management within hospitals', Academy of management Review, Vol. 11, No 1, pp. 41-54.

Fetter, R.B.(1991) "Background" in DRGs, Ann Arbor, Health Administration Press.

Ferlie, E. (1994) "The creation and Evolution of quasi-markets in the public sector: early evidence from the NHS", Policy and Politics, vol. 22, No 2.

Flynn, R. and G. Williams (1997) Contracting for health - quasi-markets and the NHS, Oxford Univ. Press, UK, pp.82.

Garattini et al. (1999)'A model for calculating costs in hospital wards: an Italian experience', Vol.13, No 2.

Greenwood, R. and C.R. Hinings (1988) "Understanding Strategic Change: The Contribution of Archetypes. Academy of Management Journal, Vol. 36, p. 10521081.

(1993) "Organisational Design Types, Tracks and the Dynamics of Strategic Change", Organisational Studies, Vol. 9, No 3, p. 293-316.

Habermas, J. (1984) The Theory of Communicative Action Volume 1: Reason and of Society, McCarthy, T. (translate), Heinemann, London.

Halgand, N. (2000) "The Hospital Accounting reform in France: Which Performance Model for Health care providers?, Paper presented to the CIMA Workshop, September, p. 21-22.

Ham, C. (1999) Health policy in Britain, The Politics and Organization of the National Health Service, $4^{\text {th }}$ Ed, Macmillan Press, London.

Jacobs, K. (2001) 'Exploring the role of accounting in Medical Education: Mediating the professional and the bureaucratic', Paper presented in CIMA Workshop, University of Edinburgh, 27-28 ${ }^{\text {th }}$ September.

Johnson, H. and R. Kaplan (1987) "Relevance Lost - The rise and fall of Management Accounting", Boston, Massachusetts: Harvard Business Scholl press.

Jones, C.S. (1999) 'Developing financial accountability in British acute hospitals', Financial Accountability \& management, Feb, Vol. 15, No 1, pp.1-20.

(2002) "The attitudes of British National Health Service Managers and Clinicians towards the introduction of benchmarking.", Financial Accountability and Management, Vol. 18, No 2, May, p.163-188.

Jones, C.S. and I.P. Dewing (1997) The attitudes of NHS Clinicians and Medical Managers towards changes in accounting controls', Financial Accountability and Management, Vol.13, No. 3 p. 261:280.

Kitchener, M. (1998) "Institutional change in UK Hospitals', Public Administration, Vol. 76 No 1, p.73-95.

Knights and Collinson (1987) "Disciplining the Shopfloor: A Comparison of the Disciplinary effects of Managerial \{psychology and Financial Accounting", Accounting, organizations and Society, Vol. 12, No 5, p. 457-477. 
Kurunmaki, L. (2001) 'A Hybrid Profession - The Appropriation of Management Accounting Expertise by Medical Professionals', Conference Paper presented in CIMA Workshop, University of Edinburgh, 27/28 ${ }^{\text {th }}$ September.

Lapsley, I. and A. Pettigrew (1994) "Meeting the challenge: Accounting for change", Financial Accounting Management, vol. 10, No 2, p. 72-92.

Lapsey, I. (1997) 'The New Public Management Diaspora: The Health Care Experience', International Association of Management Journal, Forum on Research in Health Care Management, Vol. 9, No 2, p.1-19.

(2001) 'Accounting, Modernity and Health Care Policy', Financial Accountability \&Management, Vol. 17, No 4, p. 331-50.

Laughlin, R. (1991) "Environmental disturbances and organisational transitions and transformations: some alternative models', Organization Studies, Vol. 12, No 2, pp. 209-232.

(1995) 'Methodological Themes - Empirical Research in accounting: alternative approaches and a case for 'middle-range' thinking', Accounting, Auditing \& Accountability Journal, Vol. 9, No 1, pp. 63-87.

(2004) "Putting the record straight: a critique of 'methodology choices and the construction of facts: some implications from the sociology of knowledge", Critical Perspectives on Accounting, Volume 15, Issue 2, February, p. 261-277.

LeGrand, J. and B. New (1996) Rationing in the NHS - Principles and Pragmatism, King's Fund, London.

Lehtonen, T. (2000) "In search of efficiency - DRG-Based pricing and case-mix accounting", Helsinki School of Economics and Business Administration, Dept. Accounting and Finance.

Llewellyn, S. (1998)'Pushing budgets down the line:"Accounting, Auditing and Accountability Journal, Vol. 11, No 3, p. 292-308.

Llewellyn, S. and D. Northcott (2001) 'X-ray vision', Financial Management, Dec., p.36-37.

Northcott, D. and S. Llewellyn (2003) "The 'Ladder of Success' in Healthcare: The UK National Reference Costing Index" (2003) Management Accounting Research, Vol. 14, No 1, pp. 51-66.

Nyland, K. and I. Pettersen (2004) 'The control gap: The role of budgets, accounting information and (non-) decisions in hospital settings', Financial Accounting \& Management, Vol. 20, No 1.

Pettersen, I. (2001) 'Implementing management accounting reform in the public sector: the difficult journey from intentions to effects', The European Accounting Review, Vol.10, No 3, p. 561-581.

Propper, C. and W. Bartlett (1997) 'The impact of competition on the behaviour of NHS Trusts' in Flynn and Williams (1997) Contracting for health - quasi-markets and the NHS, Oxford Univ. Press, UK, pp.82

Preston et al. (1992) 'Fabricating budgets: a study of the production of management budgets: a study of the production of management budgeting in the NHS', Accounting, Organizations \& Society, vol. 17, No 6, pp. 561-593.

Purdy, D. (1995) "Control and the NHS: some psychology of managing healthcare with cash budget and cash limits" in Berry A. et al. (1995), Management Control, Theories, Issues and Practices, McMillan, London.

Ryan, B. et al. (2002) Research Method \& Methodology in Finance and Accounting”, Academic Press Limited, London.

Richardson, S. and J. Cullen (2000) "Autopsy of change: contextualising entrepreneurial and accounting potential in the NHS, Financial Accounting Management, Vol. 16, No 4, p. 353-372. 


\section{Labour Legislation and Policies:}

1997 White Paper "The NHS - Modern and dependable", The Stationary Office, DoH.

1999 White Paper "Our Healthier Nation", The Stationary Office, DoH.

First Class Service (1999) - The Stationary Office, DoH

Health Service Circular (HSC 1999/098) National Schedule of Reference Costs, June 1999, NHS Executive.

Health Service Circular (HSC 1998/163 - NHS Executive

Health Service Circular (HSC 1998/198) 'Commissioning in the new NHS', Commissioning Services 1999-2000, 1 November 1999, NHS Executive.

Health Service Circular - HSC 1999/243 - Health Authority Revenue Cash Limits 2000/01Introducing the Healthcare Framework, Casemix Office, NHS Executive.

High Level Performance Indicators (1999) The Stationery Office, DoH, June.

National Schedule of Reference Costs - Costing and Activity requirements, June 2000 Collection - NHS Executive.

NHS Costing Manual - January 2000- NHS Executive

The NHS Performance Ratings for Acute Trusts (2000/2001)

Waiting Team Action Team - Getting Patients Treated - The Waiting List team Handbook August 1999 - NHS Executive

\section{NHS Trust's Documentation}

Annual Report 1998-1999; 1999-2000; 2000-2001; 2001-2002

Finance and Activity Reports (2000;2001; 2002; 31/03/03)

The Trust's Performance Profile 1998/9 (Feb 2000) - Audit \& Commission-Promoting the best use of public money

The 1998/99 Reference Costs Internal Report

The ninetieth to twenty-sixth board meeting reports (from June-1999 to January 2002).

Progress Report, 2001/02 - Finance Plan

\section{APPENDIX}

Accident \& Emergency (A\&E)

Department of Health (DoH)

Diagnosis Related Groups (DRGs).

Health Authority (HA)

Health Benefit Groups (HBGs)

Health Resource Groups (HRGs)

Health Improvement Programmes (HImPs)

Health Services Circular (HSC)

Financial Managers (FMs)

Long-Term Service Agreements (LTSAs)

National Health Services (NHS)

National Reference Costing Exercise (NRCE)

National Schedule Reference Costs (NSRC)

National Performance Framework (NPF)

National Reference Costs Index (NRCI)

Primary Care Groups (PCGs)

Service Financial Framework (SaFFs) 
IItr-clydelusers\dilalMy Documents\DILA2\Dila\PUBLICATIONSIPAPERS\FAMIDila FAM WorkingPaperSoton13 Sept 05.doc 